2013 - Vol. 8 - Número VIII - Resistencia, Chaco, Argentina. Pp. 108 - 124

\title{
Estudio sociológico sobre la sociedad granadina (España) tras la aparición del cine
}

\author{
Salvador Mateo Arias Romero
}

Universidad de Granada (España)

Recibido: 25/07/2013

Aceptado: $22 / 08 / 2013$

\section{Resumen}

Tanto el cine como los medios de comunicación en general hemos de verlos como agentes socializadores, influyendo estos en los comportamientos y actitudes sociales del ser humano. La sociedad Granadina a principios del siglo XX se planteó el peligro que podría encerrar el nuevo espectáculo de masas, ya que eran conscientes de la transmisión de nuevos valores que pueden llegar a transformar la sociedad.

Uno de los aspectos valorados en este estudio ha sido la realización de un ensayo histórico y social con el que pretendemos resaltar el impacto que tuvo en la sociedad el cinematógrafo, hasta el punto de aparecer regularmente en prensa y otros tipos de publicaciones periódicas, incluyendo un apartado diario para publicitar las carteleras.

Además de la condición artística del cine, no podemos dejar de reseñar su función primigenia: la de informar. Durante los siglos XIX y principios del XX, se produjo un gran avance en los medios de comunicación, proceso fundamental para el desarrollo cultural, político, social y comercial de la sociedad.

Granada, no menos conservadora que otras ciudades del resto de España, alzaría su voz en multitud de ocasiones contra los peligros del cine y las consecuencias nefastas que este suponía para la educación de los menores. Sin embargo, frente a esa Granada conservadora, y gracias a la Universidad, existía un selecto grupo de intelectuales que lo aprobaban. No debemos olvidar que eran los años de esplendor del Liceo y por esta época Falla se asentaba en la ciudad: "Son los años en que Federico García Lorca publica su primera composición en el 
Q Nueva Etinexaxio Revista Digital de OFilosofia ISSN 1850-3578 2013 - Vol. 8 - Número VIII - Resistencia, Chaco, Argentina. Pp. 108 - 124

Boletín del Centro Artístico (enero de 1917) y nace la tertulia de 'El Rinconcillo' en un café de la plaza del Campillo" ${ }^{1}$.

Palabras Clave: Sociedad, Cine, publicidad, peligrosidad, educación.

\section{Abstract}

Both, the film and the media in general have see them as socializadores agents, influencing behaviors and social attitudes of the human being.

Society of Granada at the beginning of the 20th century faced with the danger that could lock up the new show of masses, since they were aware of the transmission of new values that can transform society.

One of the aspects valued in this study has been the realization of a social and historical essay with which we intend to highlight the impact that had on society the cinema, to the point of appearing regularly in press and other types of periodicals, including a section of the journal for advertising the billboards.

In addition to the artistic status of cinema, can not review its primitive function: the report. During the 19th and beginning of the 20th, there was a breakthrough in the media, fundamental process for the cultural, political, social and commercial development of the society.

Granada, no less conservative than other cities in the rest of Spain, would rise up your voice on numerous occasions against the dangers of the cinema and the harmful consequences that this supposed for the education of children. However, facing this conservative Granada, and thanks to the University, there was a select group of intellectuals who approved of it. We must not forget that they were the splendor years of the Liceo and by this time Falla was situated in the city: "Are the years in which Federico García Lorca published his first composition in the artistic Centre newsletter (January, 1917) and was born the social gathering of 'El Rinconcillo' in a coffe on the plaza del Campillo". ${ }^{2}$

Keywords: Society, cinema, advertising, danger, education.

\section{Los inicios del Cine}

\footnotetext{
${ }^{1}$ GAY ARMENTEROS, Juan y VIÑES MOLLET, Cristina. Historia de Granada, la Época Contemporánea. Tomo IV. Granada, Don Quijote, 1982. p. 368.

${ }^{2}$ Ibidem.
} 
Pverea Etinexaxio Revista Digital de OFilosofla ISSN 1850-3578 2013 - Vol. 8 - Número VIII - Resistencia, Chaco, Argentina. Pp. 108 - 124

Los lazos existentes entre el cine y la sociedad son duraderos y persistentes a lo largo de la historia. En el siglo XIX, y a principios del XX, Granada era una ciudad tranquila. La monotonía de la vida de sus habitantes en la mayoría de las ocasiones se veía alterada únicamente gracias a las festividades, en las que solían volcarse todos: se engalanaban las calles, los granadinos se acicalaban y salían de sus casas, tratando de olvidar los problemas cotidianos de una vida bastante más dura de la que hoy en día conocemos.

Las gentes de Granada siempre destacaron por ser amantes del teatro y este amor rápidamente fue compartido con el cine. Prueba de ello es que, junto con Sevilla, Granada es la ciudad que mejores edificios ha construido para albergar este nuevo espectáculo.

El cine tuvo, y tiene, un gran poder sobre los espectadores, llegando incluso a cambiar costumbres y a unificar estilos de vida muy diferentes. También ha servido como elemento propagandístico en época de guerras, proporcionando falsas lecturas de la historia en algunas ocasiones.

Se exhibe actualmente en Madrid, en la Carrera de San Jerónimo 34, antiguo local del Bazar de Ibo Esparza, un sorprendente aparato llamado 'el cinematógrafo' que como indica su nombre (del griego Kinéma Kinématos, el movimiento y grafo, yo pinto o escribo $=$ pintura del movimiento) no es otra cosa que la fotografía animada de tamaño natural, obtenida gracias al invento de los Señores Augusto y Louis Lumière. $^{3}$

Este artículo continúa con una explicación más o menos científica del maravilloso y sorprendente invento que fue, y podemos decir que sigue siendo, el cinematógrafo. Según el Dr. Nothing, redactor del primer artículo en la prensa granadina sobre cinematografía, el principio científico de dicho aparato se basa en la persistencia de las impresiones luminosas en nuestra retina. Dicho principio había sido demostrado de mil formas distintas, entre otras haciendo girar un carbono o mecha encendida con el brazo, trazando así rápidas vueltas que, gracias a la velocidad, nos dejan ver una circunferencia luminosa. Este hecho se puede aplicar a mil usos de la vida cotidiana, como pueden ser las ruedas de fuego de los castillos de pirotecnia. Las aplicaciones que se conocían hasta el momento y en las que hace hincapié el redactor eran:

\footnotetext{
${ }^{3}$ DR. NOTHING. “El Cinematógrafo". En: El Defensor, Granada, 11 de julio de 1896, no 9.189, p.1.
} 


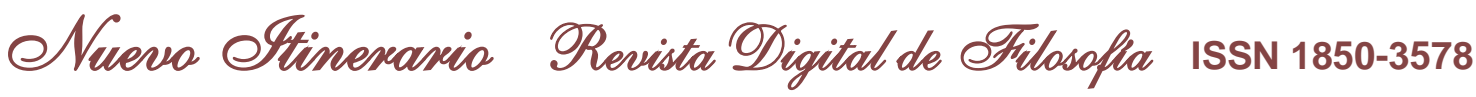
2013 - Vol. 8 - Número VIII - Resistencia, Chaco, Argentina. Pp. 108 - 124

1- las siluetas negras que reaparecen blancas, al fijar la vista en el techo de una habitación. Técnica, por otro lado, muy generalizada en la época.

2- También estaba el zootropo, que consiste en un aparato cilíndrico, móvil alrededor de un eje vertical, con unas hendiduras equidistantes y verticales, a través de las cuales se ven figuras dibujadas en un papel, que parecen moverse cuando gira el aparato, debido a la persistencia de las imágenes en la retina.

3- También existían infinidad de juguetes, bastante generalizados, en los que se colocaba una estrella fija de papel con figuras en distintas posiciones y movimientos sucesivos, lo que permitía que al girar el aparato, se produjera la visión aproximada del movimiento simple que representa el dibujo, como es un salto, un baile, etc.

No sabemos si con este artículo los lectores de finales del siglo XIX entendieron muy bien el mecanismo del cinematógrafo, pero de lo que sí podemos estar seguros es de la expectación que provocó: para muchos granadinos, aquello debió de ser algo completamente mágico.

Un día después de la aparición de la primera noticia sobre la existencia del cinematógrafo en la prensa granadina, aparecía otro artículo al respecto. En este segundo artículo, publicado el 12 de julio de 1896, el periodista Dr. Nothing se centraba en la descripción del inmueble en el que se exhibía el nuevo artilugio, realizando igualmente una concienzuda descripción de las películas o documentales que se proyectaban.

Según Nothing, el local estaba completamente tapizado con paños oscuros para evitar la difusión de la luz. Su iluminación era eléctrica. Cuando el recinto se quedaba a oscuras, se encendía el cono de proyección, apareciendo las escenas. Al concluir (teniendo cada una, una duración aproximada de un minuto) reaparecía de nuevo la iluminación en la sala.

En el fondo del salón se hallaba, algo elevada del pavimento, una gran pantalla sobre la que se dibujaban las fotografías animadas, presentadas entre cortinas y paños carmesíes, elegantemente alejada del público por un parterre de macetas de plantas de admirable golpe de vista pictórico. A continuación, nos encontrábamos con las sillas para el público y detrás, en una especie de palco elevado, se hallaba el aparato proyector, oportunamente oculto de la vista del público, y del que no se mostraba otra parte que el objetivo, apareciendo a través de un simple agujero y coincidiendo en línea recta con el centro de la pantalla.

(...) La proyección se verifica por encima del público y directa sobre la cara externa de la pantalla, no por transparencia como ocurre en los cuadros 
Pverea Etinexaxio Revista Digital de OFilosofla ISSN 1850-3578

2013 - Vol. 8 - Número VIII - Resistencia, Chaco, Argentina. Pp. 108 - 124

disolventes. Las vistas que se exhiben, y que se hallan convenientemente anunciadas en los testeros del salón, son en número de diez. ${ }^{4}$

Todo el afán de Nothing era transmitir lo mejor posible al público granadino el nuevo invento que se exhibía en Madrid. Para ello también describía algunos de los mejores cuadros que se estaban proyectando.

El Cine evolucionaría a pasos agigantados perfeccionando su técnica pero desde su aparición hasta la primera proyección de una película hablada aún tendrían que pasar algunas décadas. Según Román Gubern,

la implantación del cine sonoro en España coincide con el desplome del Régimen Monárquico y el establecimiento de la Segunda República, que nació el 14 de abril de 1931, a raíz de las elecciones municipales que demostraron la impopularidad en las ciudades de una corona que había propiciado la dictadura del general Miguel Primo de Rivera, desde septiembre de 1923 a enero de $1930 .^{5}$

Como es bien sabido, el cine nunca ha estado ajeno al sonido, siempre ha estado acompañado de música, potenciando sus imágenes, especialmente en los momentos críticos del argumento filmo gráfico.

En la historia del Cinematógrafo Mágico Pascualini (cinematógrafo Itinerante. 1904), los vecinos del Embovedado del Darro se quejaban del ruido que producía el órgano en este cinematógrafo, un ruido que calificaban de monótono y aburrido. Ante las quejas, Pascualini se comprometió a tocarlo sólo en los entreactos, lo cual no era lo normal, pues la tendencia consistía en que la música amenizara toda la película. Cuando contemplamos una película de Chaplin, vemos cómo sus momentos de aceleración son más dinámicos gracias a la utilización de la música e igualmente sucede con los momentos melancólicos o de relax.

Las salas de estreno, situadas en los lugares más céntricos de la ciudad, fueron, y algunas de ellas siguen siendo, lujosos locales que precisaron fuertes inversiones. Contaban en nómina con un gran número de empleados, entre los que se incluían músicos, proyeccionistas, personal de mantenimiento, acomodadores e, incluso en ocasiones, como ocurrió durante la proyección de la película Helga (especie de documental sobre el parto) en el Cine "Príncipe", se llegaría a contratar a una enfermera para asistir a las personas que sufrían

\footnotetext{
${ }^{4}$ DR. NOTHING. "El Cinematógrafo". En: El Defensor, Granada, 12 de julio de 1896, no 9.189, p.1.

${ }^{5}$ ROMÁN GUBERN, José Enrique. Historia del Cine Español. Madrid, Cátedra, 2000. p. 123.
} 


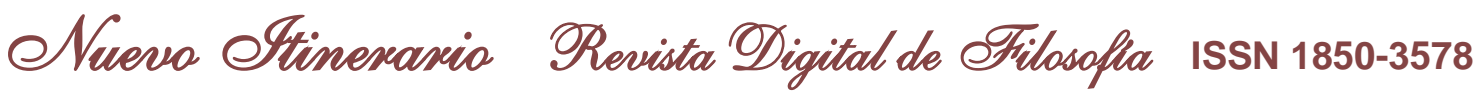
2013 - Vol. 8 - Número VIII - Resistencia, Chaco, Argentina. Pp. 108 - 124

desvanecimientos tras contemplar la proyección. Con el paso del tiempo, las plantillas empezarían a reducirse, comenzando por los músicos, innecesarios tras la llegada del cine sonoro.

Las salas de cine son lugares limitados, lugares cerrados. Las condiciones en las que se presencia el espectáculo cinematográfico difieren de la mayoría de los espectáculos, pues los espectadores aún estando juntos, están al mismo tiempo separados por la oscuridad y aislados unos de otros por la atracción que ejerce la pantalla. Al espectáculo cinematográfico se accede sin necesidad de ir demasiado engalanado, como ocurría en el teatro, y sin necesidad de ir acompañado y, sobre todo, sabiendo que se trata de algo ficticio. No obstante, en el transcurso de la proyección de una película, los espectadores suelen convertir la película en realidad, dejando volar su imaginación y creyéndose protagonistas de los acontecimientos proyectados, sintiéndose poseedores de modelos de vida en la mayoría de las ocasiones bastante alejados de su realidad cotidiana (es lo que se suele denominar "la magia del cine").

\section{El cine como medio de comunicación social: la publicidad.}

"El cine es la comunicación a través de imágenes, las múltiples dimensiones que alberga este medio de comunicación posibilitan una riqueza narrativa, lo que lo ubica como el arte y el medio de expresión característico del siglo XX" ${ }^{6}$

El objetivo primordial de la publicidad es informar al público sobre la existencia de bienes a través de los diferentes medios de comunicación. Se suele confundir el término publicidad con el de propaganda; hemos de decir que esta última pretende la divulgación de ideas políticas, sociales, religiosas sin fines estrictamente económicos.

El cine desde sus comienzos fue un medio de masas muy consciente de la importancia de la publicidad creando incluso sus propios sistemas. La cartelera sería el principal medio publicitario adoptado por los cinematógrafos para anunciar las películas. Durante años las fachadas de estos inmuebles fueron engalanadas con enormes anuncios de filmes que requerían la atención del viandante.

El procedimiento de realización no es nada complicado, en primer lugar se montaba la tela sobre los bastidores de madera; el número de bastidores obedecía en gran medida al espacio de la fachada dedicada al anuncio, que variaba dependiendo de los cines. Una vez realizado esto, se pintaba la tela con temple blanco aguado con cola de conejo muy rebajada para que

\footnotetext{
${ }^{6}$ http://www.creatividadinternacional.com/forum/topics/el-cine-como-medio-de-comunicaci-n . (Fecha de consulta: 10-VII-2013).
} 
Q Nueva Etinexaxio Revista Digital de OFilosofia ISSN 1850-3578 2013 - Vol. 8 - Número VIII - Resistencia, Chaco, Argentina. Pp. 108 - 124

se pudiera tensar. Sobre ella se trazaba una cuadrícula con un lápiz, en proporción al paño de cartelera. La cuadrícula ayudaba enormemente a la hora de reproducir la imagen. Una vez realizados todos estos pasos se comenzaba a pintar.

"Una cartelera no es más difícil que otra, pero la cantidad de trabajo varía. Las más laboriosas son aquellas que tienen más figuras. El resultado depende mucho de la calidad de la foto o el afiche de la película (...). Si no es bueno, casi tenemos que inventar nosotros la imagen".7

Los propietarios de los cines decidían el cambio de programación los lunes si la taquilla del fin de semana no había sido buena, es por ese motivo por el que la realización de las carteleras debían hacerse deprisa porque tenían que estar listas para el jueves, día en que se anunciaban las nuevas proyecciones.

El paso de los grandes cines a los multicines, fue el responsable de la desaparición de las grandes carteleras, en la actualidad se anuncian con los fotogramas, ahorrando costes, igualmente son utilizados diferentes medios propagandísticos como la radio, televisión e Internet, llegando esta información a todos los hogares y acaparando de este modo a un mayor número de espectadores.

Las carteleras eran trabajos efímeros, una vez retirada la película, la cartelera se reciclaba, lavando las telas para que de ese modo desapareciera la pintura al temple y volviendo a montarlas de nuevo en los bastidores.

Otro medio publicitario importante junto con las carteleras serían los denominados programas de mano. Estos programas aparecen una vez que el cine se ha consolidado, desapareciendo cuando la televisión llega a los hogares.

En mi opinión, la definición más exacta y reveladora de los objetivos de estos pequeños papeles debería haber contenido la palabra Anuncio, ya que, en realidad, la misión de los mismos consistía en comunicar todos aquellos aspectos que facilitaran el tráfico de público hacia la cinta en cuestión: Sala de proyección, título del filme, principales intérpretes, fecha y horario de las diferentes funciones. ${ }^{8}$

En el caso de Andalucía estos programas recibirán el nombre de Prospectos. La gran mayoría consistían en la reducción del cartel a formato de bolsillo. Del mismo modo que los primeros

\footnotetext{
${ }^{7}$ NOGUEIRA, Charo. .http://www.elpais.com/articulo/madrid/MADRID/Gran/Via.(Fecha de consulta: 18VII-2013).

${ }^{8}$ BAENA PALMA, Francisco. Los Programas de Mano en el Cine. Barcelona, Papel Gallery, 2004. p. 33.
} 


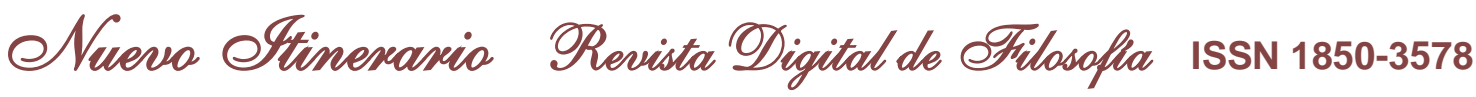
2013 - Vol. 8 - Número VIII - Resistencia, Chaco, Argentina. Pp. 108 - 124

inmuebles cinematográficos copiaron formas espaciales de los teatros, inicialmente el contenido de los programas de mano (a imitación del de los teatros), se centraría en describir mediante un pequeño resumen el argumento principal de la película.

Pronto renunciarán a ser distribuidos exclusivamente en el interior de las salas, siendo repartidos en los puntos más transitados de las ciudades; dejando de presentar únicamente la sinopsis de la película e incluyendo el nombre de la sala, día de inauguración, fechas en cartel, horario de las diferentes funciones, así como publicidad de algunos comercios. Un ejemplo claro lo tenemos con el estreno en el Coliseo Olympia de Café Metropol el 12 de abril de 1941. Los programas que publicitaban películas nacionales divulgaban los nombres de Miguel Ligero, Estrellita Castro, Imperio Argentina... de idéntica forma ocurría con los actores de películas extranjeras, potenciando de este modo un mayor interés por el film.

El 25 de enero de 1945 se estrena en el Cine Aliatar El 4 Mandamiento, utilizando un díptico en cuyo anverso aparecía el título de la película y Orson Welles como el "mago" de una nueva técnica y en el reverso el título del cine en el que se proyectaba, día del estreno y un breve extracto del argumento de la película. Una vez que se abría el díptico, en su interior aparecía de nuevo el nombre del director, así como los de los principales actores, mostrándonos sus rostros a todo color.

Al igual que otras actividades de ocio, tras la guerra civil llegó la censura a los programas. Esta consistió, principalmente, en suprimir los nombres de los actores extranjeros que fueron contrarios al régimen. Como fue el caso de Joan Crawford, Franchot Tone y Robert Montgomery, por lo que en el programa aparecía la foto de los tres actores sin sus respectivos nombres, recurriendo la distribuidora a un titular que centraba la atención sobre los protagonistas: La película de las tres estrellas.

El tipo de prospecto más utilizado fue un pequeño trozo de papel que utilizaría el reverso reflejando en este el nombre de la sala, lugar y hora del estreno. El ejemplo más característico será el utilizado para la proyección de Odio, Amor y Castigo en el Cervantes, en cuyo anverso aparece un fotograma de la película a todo color y en el envés el día del estreno, etc.

Hubo una gran variedad de programas, desde una carta de presentación que se entregaba insertada dentro de un sobre, hasta los que proponían juegos aventureros al estilo del juego de la oca, o los que incluían acertijos como en el caso de la película Candida, en el que las personas que enviaran a Madrid la solución exacta, se les obsequiaría con una foto de la encantadora Nini Marshall.

Como podemos observar los programas de mano fueron unos excelentes transmisores cumpliendo con los objetivos de los cines. A medida que fueron multiplicándose las salas de 


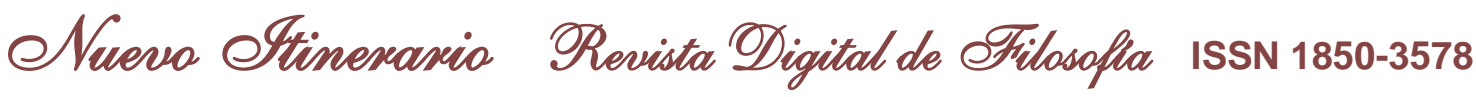
2013 - Vol. 8 - Número VIII - Resistencia, Chaco, Argentina. Pp. 108 - 124

proyección por el territorio nacional, estos acometieron grandes tiradas repercutiendo en la calidad de algunos. El modelo más habitual será el formato postal, con fotografía de baja calidad en la portada y utilizando la contraportada para la publicidad del cine, la mayoría de las veces en blanco y negro. Un dato que tuvieron muy en cuenta los empresarios es que cuantas más estrellas ilustraban el programa, mayor expectación se creaba entorno a la película.

Junto a la cartelera y los programas de mano se encontraba la publicidad en prensa. Los periódicos se caracterizaban por aportar una información cinematográfica muy variada y nada sistematizada. Los contenidos que solían aparecer se centraban en la cartelera y programación de los eventos, promoción y publicidad de los locales, así como noticias referentes a la actualidad cinematográfica. La programación de las salas de Granada se insertaban en la sección de espectáculos, promocionándose principalmente mediante la forma de anuncios por palabras. Un ejemplo lo podemos ver en el periódico El Defensor del 18 de diciembre de 1907, donde el Palais Victoria anunciaba la presencia de actores ilusionistas y la película El panadero de Venecia o un error judicial. Otro ejemplo sería el Palais Royal que aparecía en El Defensor el 28 de diciembre de 1906 como un magnífico cinematógrafo establecido en el Embovedado proyectando doce cuadros, entre ellos: Panorama de Nueva Zelanda y Un recluta de paseo.

Únicamente se podía acceder a la cartelera de aquellos locales que decidían anunciarse en prensa. Algunos cinematógrafos aparecerán de forma muy puntual coincidiendo con el inicio de la temporada. Como fue el caso del Salón de Actualidades anunciado el 29 de diciembre de 1908 en El Defensor, entre sus novedades encontrábamos la presencia de un magnífico gorila de siete colores.

Junto a los anuncios aparecía información sobre la calificación por edades de las obras como instrumento de protección de la infancia y la juventud. Este dato lo podemos confirmar con la proyección en el cine Florida de El Verdugo, anunciándose en el periódico El Ideal el 31 de diciembre de 1966 con la siguiente nomenclatura: 1- para todos los públicos, 2- mayores de 14 años, 3- mayores de 18 años, 3-R. mayores de 18 años con reparos (personas de sólida formación), 4- gravemente peligrosa. El Verdugo era clasificado 3-R. Otro de los aspectos a destacar es la escasa duración en la cartelera de los títulos, permaneciendo en cartel poco más de una semana. Los circuitos de distribución y los reestrenos, así como la necesidad constante de renovar la oferta justificarían la brevedad expositiva de las cintas en las diferentes salas.

Los grandes anuncios que ocupaban una página entera estaban reservados para el día del estreno, en estos solía aparecer la imagen de la cartelera, el nombre del cine en que se proyectaría y frases del tipo "sensacional estreno cinematográfico". Un ejemplo lo podemos 


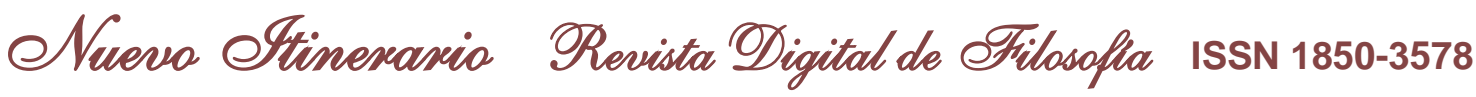
2013 - Vol. 8 - Número VIII - Resistencia, Chaco, Argentina. Pp. 108 - 124

ver con el lanzamiento el sábado 13 de marzo de 1954 en el Teatro Isabel La Católica de EI Gran Secreto.

La publicidad es un sistema de comunicación masiva que tiene por objetivo informar, persuadir y conseguir determinados comportamientos. Los empresarios cinematográficos vieron en la prensa uno de los principales medios de vender sus productos, consistiendo este tipo de divulgación en una comunicación no personal y pagada. Dependiendo del coste del anuncio, este variará en tamaño, forma e incluirá imagen junto con el texto. Del mismo modo, en los periódicos aparecían las críticas de las películas proyectadas en los diferentes cines.

En la actualidad la publicidad cinematográfica está dejando de lado a la prensa escrita para centrarse en la Red, que ofrece muchas más posibilidades, con capacidad multimedia: audio, video, música, mayor cabida de almacenaje en cuanto a textos, fotos, etc. Entrando en la Red podemos ver películas, donde aparece la duración (128 min.), día del estreno, género (drama), director, reparto, producción, guionistas, distribuidora, una sinopsis, crítica de la película e incluso un trailer, del mismo modo que las distintas salas de proyección. Otra de las ventajas es la compra de entradas por Internet.

La cartelera periodística por lo general se ha restringido a enumerar los títulos de las películas, hora y lugar de proyección. La televisión es otro medio en el que se invierte grandes sumas de dinero para lanzar colosales producciones al mercado. El cine ha estado y sigue estando en continua evolución y junto a este su sistema publicitario.

Atrás quedaron las grandes carteleras que ocupaban buena parte de las fachadas cinematográficas, estas han sido relegadas a coleccionistas y amantes del Séptimo Arte, invadiendo salas de exposiciones y museos.

\section{Peligrosidad, costumbres y educación en el cine.}

El periódico "El Defensor" protestó en diferentes ocasiones exigiendo a la autoridad gubernativa una mayor vigilancia en los espectáculos públicos; puesto que, además eso no significaba que la seguridad de la población fuera a sufrir mengua alguna, lo que parecía necesario era una correcta distribución de los servicios policiales, con más oficiales en aquellos sitios donde realmente se necesitaban, no sólo para impedir hechos delictivos, sino para que también frenaran esos escándalos bochornosos que con tanta frecuencia se producían en los salones de varietés.

El que unos cuantos ineducados vociferen a sus anchas, valiéndose de un vocabulario estúpido y grosero hasta más no poder, había que impedirlo a todo trance. 
Pverea Etinexaxio Revista Digital de OFilosofla ISSN 1850-3578

2013 - Vol. 8 - Número VIII - Resistencia, Chaco, Argentina. Pp. 108 - 124

El cinematógrafo no es una mancebía, ni una taberna, ni un centro donde se haga gala del impudor y de la desvergüenza; el cinematógrafo es, o debe ser, un espectáculo de cultura, de honradez, de moralidad, y quien con sus palabras soeces contra esto vaya, lastimando sentimientos que merecen toda clase de respetos, de allí debe salir, sin compasión alguna, en manos de los agentes de la autoridad.

Una obra de saneamiento es muy necesaria en los cinematógrafos granadinos, porque al paso que vamos sólo la gente de hampa es la que podrá asistir a los espectáculos.

Bastante desgracia es ya que el cinematógrafo no responda a la obra educativa que debiera realizar. Hay que luchar para que el cinematógrafo no se convierta en escuela de incultura, esto sin duda es tarea de la autoridad gubernativa; pero al mismo tiempo es urgente acabar con esos burdeles asquerosos que los ineducados promueven dentro de los salones donde las películas se exhiben y con las raterías que allí mismo se cometen. ${ }^{9}$

Era una demostración más del nivel cultural de la sociedad granadina, que sin duda, debió adaptarse a la aparición de un nuevo tipo de espectáculo. Un nuevo espectáculo que, en sus comienzos, no merecía aun la categoría artística que hasta el momento se le daba a las obras de teatro, óperas o conciertos; Tendrían que pasar aún muchos años hasta que el público dejara de hacer ruidos de modo voluntario ante los distintos cortes en las películas, en su mayoría debidos a cuestiones técnicas o por el simple hecho de hacer un pequeño descanso para cambiar el rollo de la película.

Un semanario local comenta en tonos de disgusto la reciente disposición del gobernador, relativa a la censura previa de las películas que se exhiben en los cinematógrafos granadinos. Sin embargo, y a pesar de las opiniones particularísimas del apreciable colega, la medida adaptada por nuestra primera autoridad gobernativa ha sido acogida con agrado y alabanza por cuantas personas cultas lamentaban y lamentan los perniciosos derroteros por los que algunas empresas de cine pretenden encaminar el gusto de los públicos. ${ }^{10}$

\footnotetext{
${ }^{9}$ Cfr. "La vigilancia en los cines". En: El Defensor, Granada, 28 de enero de 1914, no 16.551, p. 2.

10 "El cine demoledor". En: El Defensor, Granada, 13 de noviembre de 1914, no 16.840, p. 1.
} 


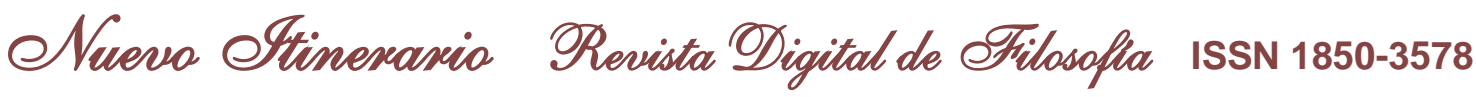
2013 - Vol. 8 - Número VIII - Resistencia, Chaco, Argentina. Pp. 108 - 124

La sociedad granadina de 1914, no era timorata, ni tímida, ni acomplejada. Por el contrario, mostraba una gran veneración por el arte. Por ello, las tragedias de Sófocles y de Shakespeare arrancaban exclamaciones de entusiasmo, mientras que los dramones por entregas hacían sonreír primero e indignaban después, al tomar consciencia del efecto pernicioso que podían causar entre los espectadores de deficiente cultura.

Cuando leemos artículos de este tipo, escritos a comienzos del pasado siglo, nos preguntamos qué dirían estos granadinos, si hoy en día se sentaran en sus salones y encenderían el televisor. Estamos seguros de que seguirían pensando de igual modo, así como la mayoría de los españoles amantes del cine, del buen cine, pensamos lo mismo que nuestros antepasados, y nos sentimos ofendidos ante tanto culebrón barato. Afortunadamente, cada vez tenemos mejores directores de cine, que saben sacar lo mejor de nuestros actores, que saben llegar a nuestro intelecto y a nuestros corazones con grandes producciones que nos hacen sentir orgullosos tanto dentro como fuera de nuestro país.

(...) Leemos con agrado los cuentos de Bocio y los mejores de nuestras novelas picarescas, nos asquea esa literatura pornográfica que trasciende a burdel y entre cuyas páginas pudieron encontrarse los gérmenes de la degeneración de las razas. Por eso protestamos contra la frecuencia con que en los cinematógrafos granadinos se exhibían películas de una insoportable noñez inmoral, y aplaudimos a las mismas empresas cuando nos dieron cintas tan dramáticas y a veces tan naturalistas como la Muerte civil, ¿Quo Vadis?, Espartaco, Los últimos días de Pompeya, etc., pero en las que la reproducción de algunas escenas algo escabrosas, quedaba compensada con hartura por el interés histórico o novelesco del argumento, y por el arte desplegado en la confección de la película.

Cuando esas circunstancias desaparecieron, cuando sólo quedó en las cintas que se exhibían la inmoralidad grosera, revistiendo diferentes aspectos, pero siempre injustificada, perniciosa y estúpida, formulamos nuestra protesta, recogiendo el espíritu y reflejando los deseos de la opinión culta y sensata de Granada, y tuvimos la fortuna de que el señor Soler y Casajuana atendiera aquellas indicaciones. ${ }^{11}$

\footnotetext{
${ }^{11}$ Ibidem.
} 


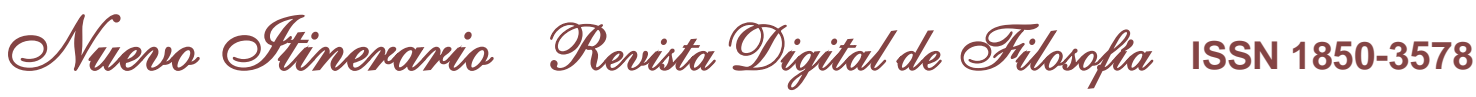
2013 - Vol. 8 - Número VIII - Resistencia, Chaco, Argentina. Pp. 108 - 124

Tras las continuas exigencias del público granadino, lo que hizo el señor gobernador, garantizando de ese modo su responsabilidad moral, fue poner en práctica uno de los requisitos que como gobernador tenía, es decir, la obligación de exigir en las exhibiciones cinematográficas lo dispuesto en la Real Orden de 15 de febrero de 1908, la Real Orden de 27 de noviembre de 1912, el Reglamento de espectáculos de 19 de octubre de 1913, la Real orden de 31 de diciembre de 1913 y la Real orden que apareció en la Gaceta de 3 de enero de 1914.

Con ello no se pretendía que los granadinos fueran al cine a recibir lecciones de moralidad. Lo que se ambicionaba era que el cine se convirtiera en un medio eficaz de cultura y de agradable pasatiempo, y no en una escuela de criminalidad, exhibición de robos, suicidios, asesinatos y continuos adulterios, sin ningún interés dramático y artístico. Se había advertido que cuando se proyectaban películas repugnantes, nauseabundas, disminuía la concurrencia, no solamente en las localidades distinguidas, sino también en la entrada general, quedando para presenciar este tipo de exhibiciones únicamente la golfería de Granada. Ya en marzo de 1914, el Gobernador prohibió en absoluto las exhibiciones de películas cinematográficas que representaran crímenes o adulterios. Este acontecimiento fue en respuesta a las continuas campañas que se sucedían en prensa por el adecentamiento del cinematógrafo.

La exhibición de películas de crímenes espeluznantes, robos, adulterios estaba terminantemente prohibida por varias disposiciones ministeriales. Sin embargo, los gobernadores no hacían caso de tales disposiciones, aunque la prensa les recordara una y otra vez, e incluso los mismos padres de familia reclamaran contra la inconcebible y extraordinaria prostitución del cinematógrafo.

Si los gobernadores habían faltado descaradamente a sus deberes en el tema de la reglamentación de las exhibiciones cinematográficas, se cuestionaban que no sería extraño que las órdenes del señor Tejón y Marín corrieran la misma suerte que con anterioridad habían corrido diversos ministros. Por ese motivo a la vez que felicitan a la primera autoridad de Granada por su decisión, le prevén que adopte cuantas medidas sean necesarias para que el cumplimiento de dicha disposición sea eficaz. "Y evitando esto, los granadinos encontraremos en el cinematógrafo lo que hasta ahora no hemos podido encontrar: cultura y deleite. Que es, precisamente, lo que necesitamos". ${ }^{12}$

Siguiendo con el cumplimiento de la Real Orden de 27 de noviembre de 1912, sobre reglamentación de las exhibiciones cinematográficas en los espectáculos públicos, se

\footnotetext{
${ }^{12}$ Ibidem.
} 


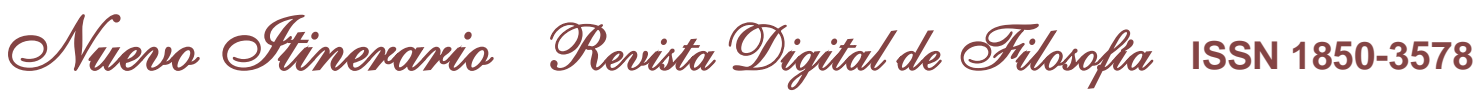
2013 - Vol. 8 - Número VIII - Resistencia, Chaco, Argentina. Pp. 108 - 124

constituyó en febrero de 1914 en nuestra ciudad una comisión dedicada a ejercer la previa censura de las películas que iban a ser proyectadas en los teatros y cines. Estas órdenes iban encaminadas a encauzar la educación y moralidad de los niños que, en boca de la opinión pública, eran los más castigados por el cinematógrafo.

Lo que con los niños se hace, lo que con la sociedad del mañana se viene haciendo en nuestros cinematógrafos, es indigno y delictivo, porque esas tiernas criaturas que tienen su entendimiento y su espíritu abiertos de par en par a todas las emociones y a todas las ideas, no recogen ni otras emociones ni otras ideas, cuando a tales espectáculos públicos concurren, que aquellas que sirven para ir enfangándolos poco a poco en la perversión más refinada y en el delito más repugnante. ${ }^{13}$

Todas estas medidas que se fueron tomando respondían a la preocupación de los granadinos por los infantes; según ellos, era indigno y criminal lo que se venía haciendo con la niñez, al presentarles películas que encerraban todo tipo de degradaciones, en lugar de ofrecerles películas que les educaran y que les instruyeran.

La selección de las películas debía realizarse de manera escrupulosa, ya que, para la sociedad del momento, ni el libro, por inmoral que fuera, ni el periódico, por obsceno que resultase, ni el mismo teatro, por degradado que estuviera, sugestionaban tanto a los niños, envileciéndolos, corrompiéndolos y dañándolos de forma tan grande como lo hacía el cinematógrafo.

Se debía luchar contra la grosería, la perversidad y el salvajismo del cinematógrafo: escuela de malas costumbres. A la infancia había que dirigirla por los senderos de la instrucción, de la moralidad y de la belleza.

Y dado que el cinematógrafo era un arma poderosísima para alcanzar dicho fin, había que hacer una obra meritoria regenerándolo y saneándolo. Este tipo de obra fue la que, en 1914 mediante la prensa, se exigiera a los integrantes de la Junta de Protección de la Infancia, encargados de asesorar al Gobernador en la selección de las películas que habían de exhibirse en los cinematógrafos públicos granadinos.

“ (...) Sería de desear que el Cine dejase de ser algo pernicioso, puesto que resta vida al verdadero teatro, y se redujese a justos límites; el de poderoso auxiliar de la educación

13 “Los niños y el cine”. En: El Defensor, 11 de febrero de 1914, no 16.565, p. 1. 
Q Nueva Etinexaxio Revista Digital de OFilosofia ISSN 1850-3578 2013 - Vol. 8 - Número VIII - Resistencia, Chaco, Argentina. Pp. 108 - 124

infantil". ${ }^{14}$ Este es el pensamiento que se tenía en 1915 sobre los cines, la visión generalizada en esta época era que el cinematógrafo se estaba convirtiendo en dominador absorbente de los teatros, cuyas salas eran merecedoras de los más importantes empeños artísticos. Por otro lado, se reconocían los enormes beneficios y los positivos bienes que el cine estaba llamado a prestar a la cultura y la educación.

El cine, por su simplificación de la vida, en sus múltiples aspectos, parece haber sido ideado para recreo y enseñanza de los niños. Es una manifestación infantil del arte, de la ciencia y de la industria, que en sus películas se exhiben. Este no es otro que el pensamiento de la época con respecto al invento del cinematógrafo. Contemplar una película sería similar a limitarse a contemplar las láminas de un libro interesante. Nos parecería completamente superficial, el hombre que, teniendo entre sus manos un volumen atrayente, lleno de ideas profundas y admirables, se limitase a hojearlo y mirar sus ilustraciones. Igualmente se podría calificar de inconscientes a las muchedumbres que, pudiendo recrearse en una buena obra dramática, prefieren la visión externa que de esa misma obra o de otra parecida le suministren las exhibiciones cinematográficas. Estarán de acuerdo conmigo en que a principio de siglo tenían parte de razón, ¿̇o quién de nosotros no ha leído un libro, luego asistido a la proyección del mismo y hemos coincidido en que el argumento del libro era mucho mejor que lo proyectado en la pantalla?

En los niños, la cuestión varía. A los niños no se les puede obligar a que asistan a la representación de la Intrusa, por ejemplo, ni a que se recreen con las páginas admirables del Fausto. Hay bastante con que miren las láminas, con que presencien frecuentemente exhibiciones de películas instructivas, que despierten en ellos la noción de las cosas y de los seres y el afán de penetrar en los secretos de la naturaleza. La verdadera misión del cine está en las escuelas y en los asilos de niños. ${ }^{15}$

Perpetuando el sentir de los granadinos con respecto al cine y los niños, hemos de alabar lo realizado por aquellas fechas en el Hospicio de Granada. Por iniciativa del diputado de la Comisión provincial, D. Antonio Guillén, todas las noches se exhibían en el benéfico establecimiento, y en presencia de los niños asilados en él, varias películas de asuntos morales, recreativas y, cómo no, siempre muy instructivas.

\footnotetext{
14 “El cine y los niños". En:El Defensor, Granada, 23 de abril de 1915, no 16.980, p. 1.

15 Ibidem.
} 


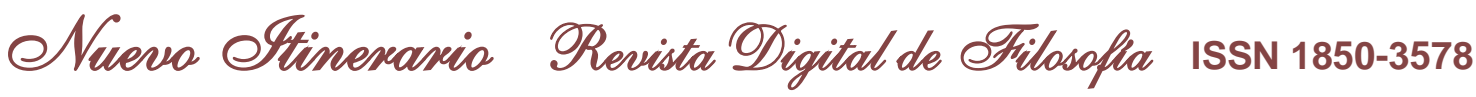
2013 - Vol. 8 - Número VIII - Resistencia, Chaco, Argentina. Pp. 108 - 124

La gestión del diputado provincial se vio secundada, desde un primer momento, por la generosa cooperación que les prestó el propietario del cinematógrafo Lux Eden, quien puso a disposición del señor Guillén, para dicho fin, de forma completamente gratuita, un aparato y un operador, enviando a diario varias películas para ser proyectadas.

En 1918 un profesor de la Sorbona consultaba a varios colegas sobre la utilidad del cinematógrafo como instrumento docente, aunque al parecer la novedad no entusiasmaba mucho a los profesores: Bocquilloy, director de una escuela de niños, pensaba que el cinematógrafo podría completar el material de enseñanza de primaria, reprochando a la Pedagogía el servirse demasiado de los libros. Un catedrático de Física sostenía que para la enseñanza de esta ciencia, lo mismo que para la de la química, era inútil la proyección de películas, con además el inconveniente de no permitir el comentario del profesor, a lo que añadía que, a lo sumo, podría servir para la representación de operaciones industriales que no pueden practicarse en el aula.

Otros dos profesores de Geografía e Historia, desestimaron la aplicación del cine en el ámbito escolar. En cambio Weill, del Instituto Luís el Grande, opinaba que era preciso e insubstituible, para dar idea de ciudades, montañas, tipos, costumbres, etc.

"La cinematografía científica ha invadido un campo curiosísimo y trascendental: el de la Microscopia, que permite enseñar con fidelidad fotográfica, los movimientos relativos a la intimidad celular". ${ }^{16}$ Entre las muchas objeciones que se esgrimían contra la cinematografía, figuraba el defecto óptico: la deformación de los objetos y aceleración su movimiento natural. El profesor que realizó la encuesta en la Sorbona, sostenía que el papel propio del cine en Pedagogía, no era enseñar, sino fijar en la imaginación la vista de lo que entraba por el oído.

Entra por la vista, y allá en la pantalla viviente de la imaginación, se fija el asunto, el argumento, la representación vivida de lo bueno y de lo malo, de lo útil y de lo estéril, si no perjudicial y nociva. La publicidad gráfica tiene también sus inconvenientes desde este punto de vista. Pero la película, con la animación de la vida, la ha desbancado, para el bien y para el mal. ${ }^{17}$

Aunque la mayoría de los profesores no encontraban prácticamente ninguna utilidad en el uso de la cinematografía aplicada a la enseñanza, sí coincidían en que se podrían proyectar películas sobre Zoología, Botánica, Anatomía, Fisiología, Geografía, Historia, etc., que siempre

\footnotetext{
16 “El cine y la escuela”. En: El Defensor, Granada, 12 de abril de 1918, no 17.579, p. 1.

17 Ibidem.
} 
QNueva Ettinexaxia Revista Digital de OFilosofia ISSN 1850-3578 2013 - Vol. 8 - Número VIII - Resistencia, Chaco, Argentina. Pp. 108 - 124

resultarían más instructiva, que las películas de corte sensacionalista, repletas de inverosimilitudes, luchas personales, y extravagancias. 